Agnieszka Tłuczak $^{1}$

Uniwersytet Opolski

\title{
Specjalizacja i konkurencyjność krajów UE w zakresie produkcji zbóż
}

\section{Specialization and Competitiveness of EU Countries in the Field of Crop Production}

\begin{abstract}
Synopsis. W artykule przedstawiono wyniki badań dotyczacych specjalizacji i konkurencyjności produkcji roślinnej w krajach Unii Europejskiej. Do badań wykorzystano metodę zmiany konkurencyjności Estebana-Marquillasa. Metoda ta pozwoliła wskazać wyspecjalizowane kraje icharakter zmian strukturalnych w zakresie produkcji upraw. Badania przeprowadzono na podstawie danych dotyczących wielkości produkcji roślinnej. Wszystkie dane zostały zaczerpnięte z baz danych Głównego Urzędu Statystycznego. Badanie obejmuje lata 2005-2016. Uzyskane wyniki pozwalają na wyodrębnienie (nierozłącznych) grup krajów specjalizujących się w produkcji poszczególnych gatunków zbóż. W zakresie produkcji pszenicy specjalizują się następujące kraje: Polska, Niemcy, Czechy, Słowacja, Włochy, Litwa, Łotwa, Estonia, Finlandia, Szwecja i Austria; zakresie produkcji pszenicy jęczmienia: Finlandia, Wilka Brytania, Niemcy, Włochy i Grecja; oraz żyta: Portugalia, Hiszpania, Francja, Wielka Brytania, Rumunia, Węry, Słowacja.
\end{abstract}

Słowa kluczowe: konkurencyjność, specjalizacja, produkcja rolna, Unia Europejska

\begin{abstract}
This paper presents the results of research on the specialization and competitiveness of crop production in European Union countries. The Esteban-Marquillas method of competitiveness changes was used for the research. This method indicates specialized countries and the nature of structural changes in the scope of crop production. The research was carried out on the basis of data on the size of crop production. All data was taken from the databases of the Central Statistical Office. The research covers the years 2005-2016. The obtained results distinguish (inseparable) groups of countries specializing in the production of particular cereal species. The following countries specialize in the production of wheat: Poland, Germany, the Czech Republic, Slovakia, Italy, Lithuania, Latvia, Estonia, Finland, Sweden and Austria; production of barley wheat: Finland, Great Britain, Germany, Italy and Greece; and rye: Portugal, Spain, France, Great Britain, Romania, Hungary, Slovakia.
\end{abstract}

Key words: competitiveness, specialization, agricultural production, European Union

JEL Classification: C23, Q13

\section{Wprowadzenie}

W gospodarce rynkowej działanie gospodarcze każdego podmiotu ekonomicznego jest związane $\mathrm{z}$ konkurowaniem $\mathrm{z}$ innymi podmiotami poprzez wykorzystanie przewag wynikających ze specjalizacji (Pawlak, 2009). Oba pojęcia: konkurencyjność i specjalizacja są pojęciami szerokimi i wielowymiarowymi, mogącymi być definiowanymi na różne sposoby z perspektywy firmy, sektora gospodarki i kraju (Tłuczak, 2016b).

${ }^{1}$ dr, Wydział Ekonomiczny, Uniwersytet Opolski, ul. Ozimska 46a, 45-058 Opole, atluczak@uni.opole.pl; https://orcid.org/0000-0001-6217-8822 
Możliwość dążenia do specjalizacji w konkretnych dziedzinach pozwala na uzyskanie wyższych dochodów poprzez wykorzystanie dostępnych zasobów. Poprzez specjalizację ekonomiczną regionu należy rozumieć posiadanie bardzo wyraźnie określonego profilu wytwórczego, z niezwykle silnie rozwiniętym działem gospodarki lub rodzajem produkowanych dóbr (Tłuczak, 2016b; Miłek, Nowak, 2014).

$\mathrm{W}$ rolnictwie pojęcie specjalizacji pozwala odpowiedzieć na pytanie, co najlepiej w danym gospodarstwie rolnym produkować i sprzedawać, aby osiagnać jak największe zyski. Wedle tak rozumianej specjalizacji jej celem jest zwiększenie ilości i jakości produkcji towarowej, wzrost wydajności pracy, osiaganie lepszej opłacalności produkcji i dochodów z gospodarstwa rolnego. Konsekwencją wzrostu specjalizacji produkcji jest zwiększenie jej dochodowości (Dziewulski, 2012; Tłuczak, 2016b).

W latach 90-tych XX wieku Tyson zdefiniował konkurencyjność, jako zdolność do wytwarzania towarów i usług, które są w stanie sprostać międzynarodowej konkurencji, podczas gdy obywatele kraju cieszą się zrównoważonym i rosnącym standardem życia (Tyson, 1992; Tłuczak, 2016b). Stankiewicz (2000) proponuje, aby konkurencyjność traktować jako system złożony z czterech podsystemów obejmujących: potencjał konkurencyjności, przewage konkurencyjną, instrumenty konkurowania oraz pozycję konkurencyjną (Nowak, 2013).

Konkurencyjność poprzez swą wieloaspektowość wyrażana może być jako zbiór unikalnych zdolności wynikających z zasobów i ich wzajemnych relacji, trudnych do osiagnięcia i naśladowania przez konkurentów (Słodowa-Hełpa, 2003). Konkurencyjność rolnictwa może być rozpatrywana $\mathrm{z}$ dwóch punktów widzenia. Po pierwsze: $\mathrm{w}$ ramach gospodarki narodowej, wówczas rozpatruje wewnętrzną konkurencyjność tego działu gospodarki. Z drugiej strony można rozważać konkurencyjność rolnictwa w ujęciu międzynarodowym, wówczas analizie poddaje się konkurencyjność potencjalną rolnictwa danego kraju (Domańska, 2013; Domańska, Nowak 2014; Woś, 2001).

Zdolności konkurencyjne danego regionu uzależnione są od sprawnego funkcjonowania systemu społeczno-gospodarczego na określonym terytorium (państwa, regionu, województwa, itp.). Taki system społeczno-gospodarczy powinien mieć zdolność do rozszerzenia reprodukcji regionalnych i krajowych zasobów, które są wykorzystywane przez dany podmiot gospodarczy - czyli wytwórcę (Wysokińska, 2002). Konkurencyjność wyraża pozycję i potencjał rozwojowy jednostki, co czyni ją predestynowaną do roli czynnika wyjaśniającego zmiany innych kategorii ekonomicznych. W literaturze przedmiotu wymienianych jest wiele metod pomiaru i badania konkurencyjności regionów (OECD, 1996; OECD 1996a). Dotychczas niedocenionym aspektem, w badaniu konkurencyjności, jest osadzenie tej relacji w przestrzeni geograficznej i próba scharakteryzowania jej z punktu widzenia zachodzących w tej przestrzeni zmian (Woźniak, 2010; Łaszkiewicz, 2014).

Celem artykułu jest zbadanie, czy na bazie potencjału wynikającego ze specjalizacji danego regionu producenci rolni korzystają z przewag konkurencyjnych na rynku. Przedmiotem badań objętych zostało 16 województw, dla których przeprowadzono analize zmian struktury produkcji roślinnej według gatunków zbóż w latach 2005-2016.

\section{Dane i metody}

Klasyczna metoda analizy przesunięć udziałów (shift share analysis SSA), zaprezentowana po raz pierwszy w latach 60-tych XX wieku przez Dunna (1960) oraz 
Perloffa, Dunna, Lamparda i Mutha (1960), wykorzystywana jest do oceny zmian konkurencyjności i specjalizacji w czasie. Metoda ta była wielokrotnie modyfikowana, m. in. przez Houston'a (1967), Berzeg'a (1978), Fothergill'a i Gudgina (1979), Stevensa i Moore'a (1980), Arcelusa (1984). W analizie SSA dokonuje się dekompozycji całkowitej zmiany zmiennej na trzy składowe: krajowy (globalny) czynnik wzrostu regionalnego; sektorowy (strukturalny) czynnik wzrostu regionalnego; lokalny (konkurencyjny, różnicujący) czynnik wzrostu $\mathrm{w}$ danym sektorze analizowanego regionu (Trzpiot $\mathrm{i}$ in., 2013; Ekonometria przestrzenna, 2010). W 1972 roku Esteban-Marquillas wprowadził do równania shift share nowego elementu, tzw. zmiennej homotetycznej $\widehat{x_{r l}}$ (EstebanMarquillas, 1972; Tłuczak, 2016a):

$$
\hat{x}_{r i}=x_{r i} \cdot \frac{x_{r}}{x_{. .}}
$$

$\mathrm{x}_{\mathrm{ri}}$ - wartość zmiennej $\mathrm{X}$ dla r-tgo regionu w i-tym sektorze;

$\mathrm{x}_{\text {.. }}$ - suma wszystkich obserwacji zmiennej X;

$\mathrm{X}_{\mathrm{r} .}$ - wartość całkowita sumy obserwacji według sektorów zmiennej $\mathrm{X}$ dla r-tego regionu.

Potrzeba zmian według Estebana-Marquillasa wynikała $\mathrm{z}$ zachodzących relacji pomiędzy pozycją konkurencyjności a efektem zmian strukturalnych, czyli poziomu i-tego wariantu zjawiska, jaki miałby r-ty obiekt, gdyby struktura zjawiska w tym obiekcie była identyczna ze strukturą krajową.

Zamiana wartości $\mathrm{x}_{\mathrm{ri}}$ wartością $\hat{x}_{r i}$ powoduje oczyszczenie efektu zmian pozycji konkurencyjności z wpływu lokalnych zmian strukturalnych. Pozostała, niewyjaśniona część rzeczywistych zmian zjawiska nazywana jest efektem alokacji:

$$
a_{r i}=\left(x_{r i}-\hat{x}_{r i}\right)\left(t x_{r i}-t x_{. i}\right)
$$

Równanie shift-share po modyfikacji przyjmuje postać:

$$
x_{r i}^{*}-x_{r i}=x_{r i} t x_{. .}+x_{r i}\left(t x_{. i}-t x_{. .}\right)+\hat{x}_{r i}\left(t x_{r i}-t x_{. i}\right)+\left(x_{r i}-\hat{x}_{r i}\right)\left(t x_{r i}-t x_{. i}\right)
$$

Składnik efektu alokacji $a_{\text {ri }}$ wskazuje czy r-ty obiekt jest wyspecjalizowany w sensie koncentracji $\mathrm{w}$ tych wariantach zjawiska $\left(x_{r i}-\hat{x}_{r i}\right)$, w których jest najbardziej konkurencyjny $\left(t x_{r i}-t x_{. i}\right)$. Wartość $\hat{x}_{r i}\left(t x_{r i}-t x_{. i}\right)$ jest uważana za wskaźnik przewagi (bądź luki) konkurencyjnej i-tego sektora w r-tym regionie w odniesieniu do obszaru referencyjnego.

Dopuszcza się brak występowania specjalizacji regionu w roku wyjściowym $\left(x_{r i}-\hat{x}_{r i}<0\right)$, a następnie wystapienie tej specjalizacji $\mathrm{w}$ roku końcowym analizy $\left(x_{r i}^{*}-\hat{x}_{r i}^{*}>0\right)$. 
Tabela 1. Charakterystyka efektów alokacji

Table 1. Characteristics of the allocation effects

\begin{tabular}{l|ccc} 
& \multicolumn{3}{c}{ Znak składników $\mathrm{a}_{\mathrm{ri}}$} \\
& Znak a $\mathrm{r}_{\mathrm{ri}}$ & $\begin{array}{c}\text { specjalizacja } \\
\left(x_{r i}-\hat{x}_{r i}\right)\end{array}$ & $\begin{array}{c}\text { konkurencyjność } \\
\left(t x_{r i}-t x_{. i}\right)\end{array}$ \\
\hline $\begin{array}{l}\text { Wyspecjalizowanie obiektu niekorzyść } \\
\text { konkurencyjności }\end{array}$ & - & + & - \\
$\begin{array}{l}\text { Brak specjalizacji obiektu niekorzyść } \\
\text { konkurencyjności }\end{array}$ & + & - & + \\
$\begin{array}{l}\text { Brak specjalizacji obiektu korzyść } \\
\text { konkurencyjności }\end{array}$ & - & - & + \\
$\begin{array}{l}\text { Wyspecjalizowanie obiektu korzyść } \\
\text { konkurencyjności }\end{array}$ & + & & + \\
\hline
\end{tabular}

Źródło: Ekonometria przestrzenna. Metody i modele analizy danych przestrzennych (2010), red. B. Suchecki, C. H. Beck, Warszawa, s. 184.

Efekt alokacji przyjmie wartości dodatnie w tych regionach, które specjalizują się w tych sektorach, w których tempo wzrostu jest większe niż wynosi globalny wzrost regionalny. I odwrotnie, jeśli tempo wzrostu w regionach jest niższe niż globalne, wówczas efekt alokacji przyjmuje wartości ujemne, a o regionie można mówić, że nie występuje w nim specjalizacja badanego zjawiska w zadanym sektorze. Im większa wartość efektu alokacji dla całego regionu tym lepiej badane zjawisko rozkłada się pomiędzy analizowane sektory. Jeśli w danym regionie nie występuje specjalizacja wówczas efekt alokacji przyjmuje wartość zero, a region nie korzysta z przewag konkurencyjnych.

\section{Wyniki badań}

Analiza struktury produkcji roślinnej została wykonana dla wybranych krajów w odniesieniu do poziomu rozwoju tego zjawiska w obszarze referencyjnym, którym były kraje UE-25 $5^{2}$. Dane wykorzystane $\mathrm{w}$ badaniu pochodzą z Rocznika Statystycznego Rolnictwa z 2016 roku publikowanego przez Główny Urząd Statystyczny (Rocznik..., 2016). W badaniach wykorzystano dane na temat wielkości zbiorów poszczególnych gatunków zbóż w tys. ton w poszczególnych krajach $(\mathrm{r}=1, \ldots, 25)$, rozważano następujące gatunki zbóż: pszenicę, żyto i jęczmień $(i=1,2,3)$.

W $2016 \mathrm{r}$. w porównaniu z rokiem poprzednim w krajach UE-25 odnotowano wzrost globalnej produkcji rolniczej o 7,1\%, który był wynikiem wzrostu produkcji roślinnej (o 10,3\%) oraz produkcji zwierzęcej (o 3,8\%). Na wzrost produkcji roślinnej wpłynęło zwiększenie zbiorów większości ziemiopłodów.

Indywidualne tempo zmian produkcji zbóż w latach 2005-2016 kształtowało się odmiennie w zależności od gatunków zbóż: pszenica, żyto, jęczmień, jak i różnorodnie dla poszczególnych krajów. W UE-25 odnotowano wzrost produkcji zbóż o blisko 33\%, w tym dla produkcji jęczmienia i pszenicy były to wzrosty na poziomie $5-6 \%$, natomiast dla żyta był to spadek produkcji o 4\%.W obrębie produkcji zbóż największe zmiany zaszły na

\footnotetext{
${ }^{2}$ Ze względu na brak kompletności danych w rozważaniach pominięto Maltę, Luksemburg oraz Cypr.
} 
Litwie i Łotwie, wzrost produkcji pszenicy wyniósł odpowiednio Litwa 175\%, Łotwa $205 \%$.

Znaczący wzrost produkcji jęczmienia obserwujemy natomiast w Danii (337\%) oraz Finlandii $(172 \%)$ i Hiszpanii $(145 \%)$. W badanym okresie odnotowano również ujemne wartości tempa zmian. Spadek produkcji żyta zaobserwować można w przypadku Finlandia (25\%), Holandii (23\%), Litwy (43\%). W pozostałych krajach w odniesieniu do pszenicy $\mathrm{i}$ jęczmienia zmiany te nie były aż tak istotne (tab. 1).

Wyodrębniona struktura towarowej produkcji roślinnej pozwoliła na przeprowadzanie analizy specjalizacji regionalnej produkcji roślinnej krajów UE-25 w latach 2005-2016. Z otrzymanych wyników można wywnioskować, że poziom specjalizacji krajów ze względu na towarową roślinną produkcję $\mathrm{w}$ analizowanym okresie był przeciętnie zróżnicowany (tab. 2).

Tabela 2. Indywidualne tempa zmian wielkości produkcji roślinnej w krajach Unii Europejskiej w latach 2005-2016

Table 2. Individual rates of change in plant production in EU countries in 2005-2016

\begin{tabular}{|c|c|c|c|c|c|c|c|}
\hline Kraj & Pszenica & Jęczmień & Żyto & Kraj & Pszenica & Jęczmień & Żyto \\
\hline Austria & $36 \%$ & $15 \%$ & $-2 \%$ & Litwa & $175 \%$ & $-30 \%$ & $-43 \%$ \\
\hline Belgia & $-21 \%$ & $-17 \%$ & $15 \%$ & Lotwa & $205 \%$ & $62 \%$ & $-23 \%$ \\
\hline Bułgaria & $63 \%$ & $7 \%$ & $5 \%$ & Niemcy & $3 \%$ & $14 \%$ & $-8 \%$ \\
\hline Chorwacja & $59 \%$ & $-2 \%$ & $61 \%$ & Pols ka & $23 \%$ & $-35 \%$ & $-4 \%$ \\
\hline Czechy & $32 \%$ & $-47 \%$ & $-16 \%$ & Portugalia & $10 \%$ & $-16 \%$ & $135 \%$ \\
\hline Dania & $-14 \%$ & $337 \%$ & $4 \%$ & Rumunia & $15 \%$ & $-47 \%$ & $68 \%$ \\
\hline Estonia & $73 \%$ & $60 \%$ & $-3 \%$ & Słowacja & $51 \%$ & $-41 \%$ & $-21 \%$ \\
\hline Finlandia & $3 \%$ & $172 \%$ & $-25 \%$ & Słowenia & $16 \%$ & $-2 \%$ & $51 \%$ \\
\hline Francja & $-20 \%$ & $-33 \%$ & $0 \%$ & Szwecja & $26 \%$ & $-10 \%$ & $-4 \%$ \\
\hline Grecja & $-17 \%$ & $12 \%$ & $74 \%$ & Węgry & $-6 \%$ & $-16 \%$ & $-3 \%$ \\
\hline Hiszpania & $60 \%$ & $145 \%$ & $73 \%$ & Wielka Brytania & $-3 \%$ & $23 \%$ & $21 \%$ \\
\hline Holandia & $-14 \%$ & $-51 \%$ & $-23 \%$ & Włochy & $4 \%$ & $63 \%$ & $-19 \%$ \\
\hline Irlandia & $-19 \%$ & $50 \%$ & $45 \%$ & & & & \\
\hline
\end{tabular}

Źródło: opracowanie własne na podstawie danych GUS. 


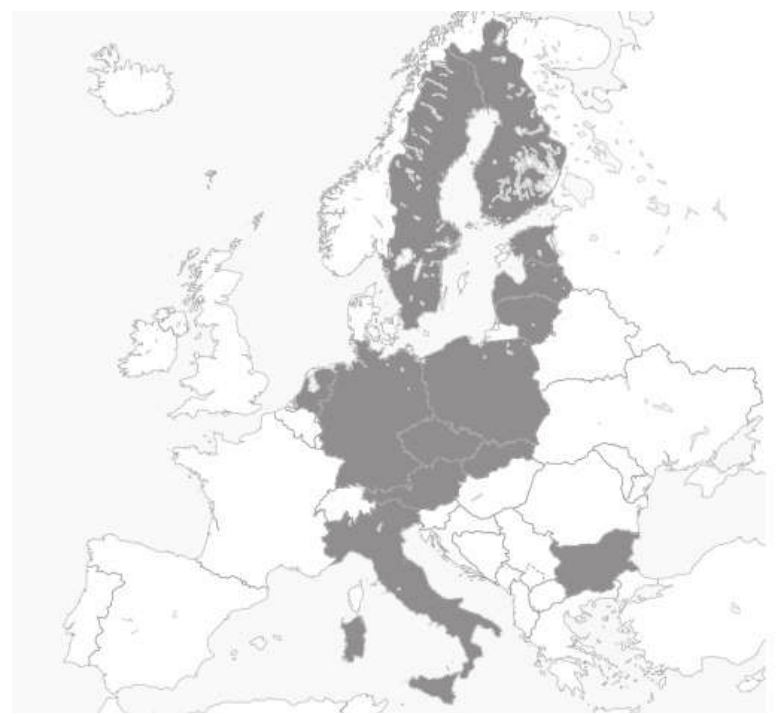

Rys. 1. Efekt alokacji dla produkcji pszenicy w krajach UE w latach 2005-2016

Fig. 1. Allocation effect for wheat production in EU countries in 2005-2016

Źródło: opracowanie własne na podstawie danych GUS.

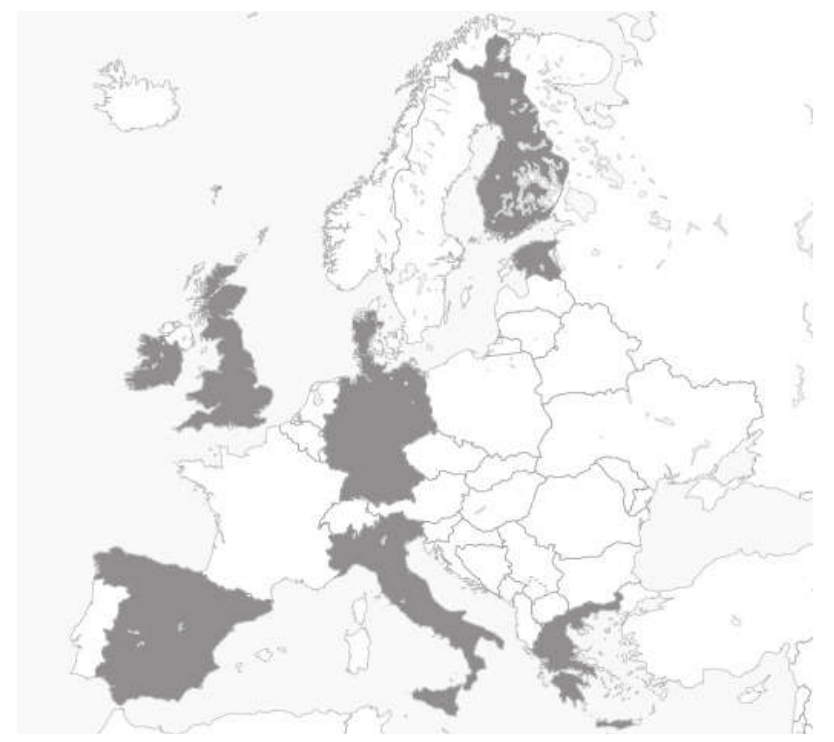

Rys. 2. Efekt alokacji dla produkcji jęczmienia w krajach UE w latach 2005-2016

Fig. 2. Allocation effect for barley production in EU countries in 2005-2016

Źródło: opracowanie własne na podstawie danych GUS. 


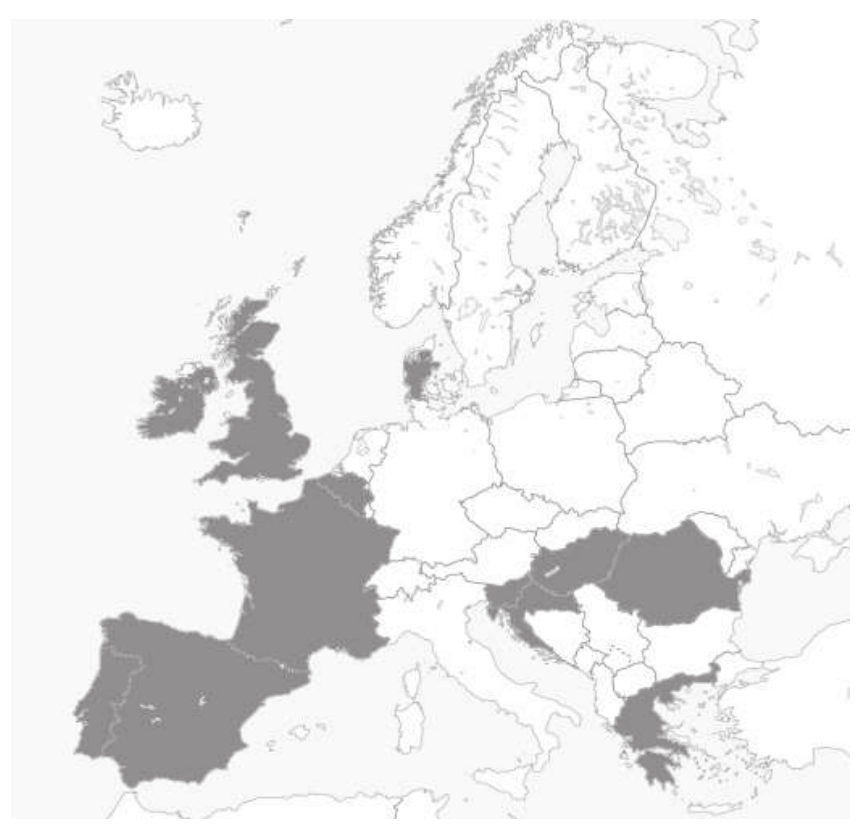

Rys. 3. Efekt alokacji dla produkcji żyta w krajach UE w latach 2005-2016

Fig. 3. Allocation effect for rye production in EU countries in 2005-2016

Źródło: opracowanie własne na podstawie danych GUS.

Rysunki 1-3 przedstawiają kraje, w których w sektorze roślinnej produkcji rolnej efekt alokacji przyjmował wartości dodatnie (szary kolor). Kraje z dodatnim efektem alokacji to jednocześnie obszary, dla których oba komponenty efektu alokacji były dodatnie. Oznacza to, że kraje te charakteryzują się wyspecjalizowaniem w zakresie produkcji pszenicy: Polska, Niemcy, Czechy, Słowacja, Włochy, Litwa, Łotwa, Estonia, Finlandia, Szwecja i Austria; jęczmienia: Finlandia, Wilka Brytania, Niemcy, Włochy i Grecja; oraz żyta: Portugalia, Hiszpania, Francja, Wielka Brytania, Rumunia, Węgry, Słowacja, przy jednoczesnej przewadze konkurencyjnej w stosunku do pozostałych krajów.

Rozpatrując wartości efektów alokacji widocznym jest, że Dania, Estonia, Finlandia, Grecja, Hiszpania, Holandia, Niemcy, Wielka Brytania oraz Włochy to kraje, dla których efekt ten przyjmuje wartości dodatnie dla dwóch gatunków zbóż. Zatem wysoka specjalizacja w zakresie tego rodzaju produkcji roślinnej wiąże się ze znaczną przewagą konkurencyjną na europejskim rynku rolnym.

W przypadku rozpatrywanych krajów nie występuje taki, dla którego efekt alokacji przyjmowałby ujemne wartości dla trzech gatunków zbóż. Nie występuje również kraj, dla którego efekt alokacji przyjmowałby wartości dodatnie dla wszystkich rozpatrywanych gatunków zbóż. Jest to z pewnością efektem świadomego użytkowania gruntów rolnych przez rolników oraz czerpanie korzyści z przewag konkurencyjnych regionu. 


\section{Podsumowanie}

Właściwa identyfikacja przewag (luk) konkurencyjnych danego obszaru pozwala na efektywne wykorzystanie potencjału regionu i dokonanie ewentualnych zmian w strukturze produkcji. Produkcja zbóż dla wielu gospodarstw rolnych jest najważniejszym źródłem dochodów, dlatego identyfikacja regionów konkurencyjnych ale także wskazanie czynników determinujących konkurencyjność zasługuje podjęcie szczegółowych badań w tym zakresie. Podjęcie właściwych działań może przełożyć się na wzrost dochodów rolniczych. Aktualny stan rozwoju rolnictwa oraz możliwości produkcyjne gospodarstw rolnych powinny być oceniane wieloaspektowo, ze szczególnym uwzględnieniem roli zbóż w zapewnieniu bezpieczeństwa żywnościowego oraz warunków przyrodniczych i organizacyjnoekonomicznych funkcjonowania rolnictwa. Przedstawione w artykule metoda badawcza pozwala na wskazanie wyspecjalizowanych krajów w obrębie produkcji roślinnej przy jednoczesnych korzyściach konkurencyjnych. Każdy rozpatrywany region w odniesieniu do obszaru referencyjnego (UE - 25) ma swoje specyficzne cechy, które wpływają na tempo i kierunki jego rozwoju gospodarczo-społecznego. Metoda zmian konkurencyjności Estebana-Marquillasa pozwala na dokonanie oceny wpływu na dany sektor kondycji całego rolnictwa oraz dokonanie oceny wpływu zmian w danym sektorze na całe rolnictwo. Przedstawione wyniki nie wyczerpują w pełni prezentowanego zagadnienia, występuje zatem potrzeba kontynuowania badań w tym zakresie.

\section{Bibliografia}

Arcelus, F.J. (1984). An Extension of Shift-Share Analysis. Growth and Change, 15, 3-8.

Berzeg, K. (1978). The empirical content of shift-share analysis. Journal of Regional Science, 18, 463-468.

Domańska, K. (2013). Konkurencyjność produkcji mleka w Polsce w ujęciu regionalnym (Competitiveness of Milk Production in Poland - Regional Approach). Roczniki Naukowe SERiA, 15(4), 105-111.

Domańska, K., Nowak, A. (2014). Konkurencyjność polskiego rolnictwa na rynku Unii Europejskiej (Competitiveness of Polish Agriculture on the European Union Market). Prace Naukowe Uniwersytetu Ekonomicznego we Wrocławiu, 361, 29-37.

Dunn, E.S. (1960) A Statistical and Analytical Technique for Regional Analysis. Papers and Proceedings of the Regional Science Association, vol. 6, 98-112.

Dziewulski, M. (2012) Poziom specjalizacji produkcji żywca wieprzowego a efektywność gospodarstw rolniczych (Level of specialization and efficiency of farms producing pigs for slaughter). Journal of Agribusiness and Rural Development, 1(23) 2012, 37-47.

Ekonometria przestrzenna. Metody i modele analizy danych przestrzennych (Spatial Econometrics. Methods and models of spatial data analysis). (2010), red. B. Suchecki, C.H. Beck, Warszawa, 162-194.

Esteban-Marquillas, J.M. (1972) Shift and Share analysis revisited. Regional and Urban Economics, 2(3), 249-261.

Fothergill S., Gudgin G. (1979) In defence of shift-share. Urban Studies, 16, 309-319.

Houston, D.B. (1967) The Shift and Share Analysis of Regional Growth: A Critique. Southern Economic Journal, 33(4), 577-581.

Łaszkiewicz, E. (2014). Wpływ konkurencyjności na poziom wynagrodzeń w krajach Europy. Analiza z wykorzystaniem modelu trendu powierzchniowego (The Influence of Competitiveness on Wages in the European Countries: Application of the Trend Surface Analysis). Acta Universitatis Nicolai Copernici Ekonomia, 45(1), 41-58

Miłek, D., Nowak, P. (2014). Specjalizacja regionalna endogenicznym czynnikiem rozwoju polskich województw (Regional specialization endogenous factor in the development of Polish regions). Working Papers 42/2014, Institute of Economic Research, revised Dec 2014. 
Nowak, A. (2013). Produktywność rolnictwa polskiego w kontekście jego konkurencyjności (The Productivity of Polish Agriculture in the Context of Its Competitiveness). Folia Pomeranae Universitatis Technologiae Stetinensis. Oeconomica, 70, 159-168.

OECD (1996). Industrial Structure Statistics 1994, Paris 1996, 17-19.

OECD (1996a). Globalisation and Competitiveness: Relevant Indicators, „STI Working Papers”, no 16/1996, Paris

Pawlak, K. (2009). Zdolność konkurencyjna polskiego sektora rolno-spożywczego w handlu wewnattrzwspólnotowym (Competitive capacity of the polish agri-food sector in intra-community trade). Zagadnienia Ekonomiki Rolnej, 3(320), 15-32

Perloff, H.S., Dunn, E.S., Lampard, E.E., Muth, R.F. (1960). Regions, resources and economic growth, Johns Hopkins Press, Baltimore

Rocznik Statystyczny Rolnictwa (Statistical Yearbook of Agriculture). (2016). Warszawa, GUS.

Słodowa-Hełpa, M. (2003). Konkurencyjność-główne wyzwanie dla polskich wspólnot lokalnych i regionalnych w zintegrowanej Europie (Competitiveness - the main challenge for Polish local and regional communities in an integrated Europe). Zeszyty Naukowe Wyższej Szkoly Bankowej w Poznaniu, 16, 111-129.

Stankiewicz, M.J. (2000). Istota i sposoby oceny konkurencyjności przedsiębiorstwa (The essence and ways of assessing the competitiveness of an enterprises). Gospodarka Narodowa, 7-8, 95-111.

Stevens, B., Moore, C.L. (1980). A critical review of the literature on shift-share as a forecasting technique. Journal of Regional Science, 20, 419-437.

Tłuczak, A. (2016a) Metoda zmian konkurencyjności Estebana - Marquillasa a specjalizacja regionu na przykładzie produkcji zwierzęcej w Polsce (Esteban - Marquillas Method of Changes in Competitiveness and Specialisation of the Region on the Example of Animal Production in Poland). Metody Ilościowe w Badaniach Ekonomicznych, 17(3), 152-160.

Tłuczak, A. (2016b) Regionalna specjalizacja produkcji rolnej w Polsce (Regional specialization of agricultural production in Poland). Studia Obszarów Wiejskich, 42, 209-216.

Trzpiot, G., Ojrzyńska, A., Szołtysek, J., Twaróg, S. (2013). Wykorzystanie shift share analysis w opisie zmian struktury honorowych dawców krwi w Polsce. Wielowymiarowe modelowanie i analiza ryzyka (The use of shift share analysis in the description of changes in the structure of honorary blood donors in Poland. Multidimensional modeling and risk analysis), UE Katowice, Katowice.

Tyson, L. (1992), Who's bashing whom: trade conflict in high technology industries, Institute for International Economics, Washington D.C.

Woś, A. (2001). Konkurencyjność wewnętrzna rolnictwa (Internal competitiveness of agriculture). Warszawa, IERiGŻ.

Woźniak, D. (2010). Identyfikacja przewag konkurencyjnych regionu. Organizacje komercyjne i niekomercyjne wobec wzmożonej konkurencji oraz wzrastajacych wymagań konsumentów (Identification of competitive advantages of the region. Commercial and non-commercial organizations in the face of increased competition and increasing consumer requirements). Vol. 9, Sowa Drukarnia Cyfrowa, Warszawa, 235-240.

Wysokińska, Z. (2002). Konkurencyjność w międzynarodowym i globalnym handlu towarami technologicznie intensywnymi (high-tech) (Competitiveness in the International and Global Trade of High-tech Products). Studia Europejskie, 1, 127-159.

\section{Do cytowania / For citation:}

Tłuczak A. (2018). Specjalizacja i konkurencyjność krajów UE w zakresie produkcji zbóż. Problemy Rolnictwa Światowego, 18(3), 323-331; DOI: 10.22630/PRS.2018.18.3.90

Tłuczak A. (2018). Specialization and Competitiveness of EU Countries in the Field of Crop Production (in Polish). Problems of World Agriculture, 18(3), 323-331;

DOI: 10.22630/PRS.2018.18.3.90 